Instructions/Template for Preparing Manuscript for Jendela Nursing Journal

\title{
Management Education (DSME) Diabetes through the Whatsapp Application in Diabetes Mellitus Type II Clients
}

\author{
Yustina Dwi Cahyanti ${ }^{1}$, Nina Indriyawati ${ }^{1}$, Shobirun ${ }^{1}$ \\ ${ }^{1}$ Nursing Study Program, Poltekkes Kemenkes Semarang, Indonesia \\ Coresponding author: yustinadwi3@gmail.com
}

\begin{abstract}
Background: Diabetes Mellitus (DM) is a chronic metabolic disease that requires selfmanagement education to prevent complications. Diabetes Self Management Education (DSME) is used as an effective method in improving the independent care of DM patients when discharged from the hospital. There are still many methods of delivering health education in several hospitals using poster / leaflet print media that are placed in strategic locations. Another method that can be done is to use the WhatsApp application.
\end{abstract}

Purpose: This study aims to determine the feasibility of health education media about DSME through the WhatsApp application on Diabetes Mellitus type II clients.

Methods: The method in this study uses Research and Development (R\&D) by using the ADDIE model development method (Analysis, Design, Development, Implementation, Evaluation). The subjects of this study were conducted by 3 experts (health promotion experts, nursing practitioners, and surgical medical nurses) and 10 clients with type II DM. In this study using a validation sheet from 3 experts by providing an assessment of the media used by researchers includes 3 aspects, including: aspects of the material, aspects of the content, and aspects of appearance.

Results: The internal validity test was carried out by 3 experts with an average percentage rating on the material aspect of $93.3 \%$, the content aspect of $95 \%$ and the display aspect of $91.6 \%$. External validity test results obtained from trials limited to 10 clients with an average percentage of results in 3 aspects, among others: 96.5\% material aspects, $95.5 \%$ understanding aspects and $96 \%$ display aspects.

Conclusion: Submission of DSME through the WhatsApp application is considered very feasible to be used as a medium for delivering material for type II DM clients because it can improve understanding of self-management when discharged from the hospital.

\section{Keywords:}

Diabetes Mellitus, DSME, WhatsApp

\section{BACKGROUND}

Diabetes Melitus type II is a metabolism conditionthat usualy grow when the body fail to prodce enough insulin or when the insulin fail to work, that called as insulin resstance. Insulin is a stimulating hormone that stimulate cell to carry glucose from blood that used to make energy (Hurtado and Vella 2019). Diabetes type II usualy 
related with obesity, diabetes family background, and physical activities. (Ansari, Dixon, and Coles 2015).

The risk of dead can be accure to DM suffering people due to compilation this think caused of DM can't cured, but not all the DM patiens get same symptom if they can control quality in their own condition in order to get healtier live, to reduce this we need diabetes management programs where there are dietary, activities and exercise. smartphone application that has a continuous effect on self- management is a smartphone application that can be used to send automated messages that serve as triggers for self-management

Therefore, it requires the ability to manage one's own behavior. This ability is often called Self Management. Diabetes Self- management Education (DSME) is a process of health education for individuals or families in managing diabetes. DSME uses guidelines, counseling, and behavioral intervention methods to increase knowledge about diabetes and in the world of health information can be an important factor in people's lives, especially to get services improve individual and family skills in managing disease DM (Fitri, Sari, and Krianto 2019).

In the world of health information can be an important factor in people's lives, especially to get health services when sick. Another type of behavior in diabetic patients. This application is called WhatsApp. Whatsapp is a social media to communicate with other users, as a tool to send or receive messages. WhatsApp users can send or receive

messages that can be used as a medium to send or receive information. (Ekadinata and Widyandana 2017).

The educational program through the use of sending text and educational images about Diabetes Self Management Education (DSME) on the WhatsApp application effectively increases knowledge. WhatsApp can be a media to improve health education based. The advantage of education using WhatsApp is that it is easily accessible and material cost effective (Fitri, Sari, and Krianto 2019). Based on the results of Dwi Elka Fitri's research, Tri Krianto, Siska Mayang Sari (2018), it was found that Diabetes Self Management Education with social media methods (whatsApp group) was more influential in improving the self care behavior of diabetes mellitus patients compared to Diabetes Self Management Education with the lecture method using a booklet. Based on the above problems, it is necessary to conduct research on the development of health education media about DSME through the WhatsApp application on type II DM clients.

\section{METHODS}

The method in this study uses Research and Development (R\&D) using the ADDIE model development method (Analysis, Design, Development, Implementation, Evaluation). The steps in this research include: (1) Potential problems and information gathering, (2) Literature studies, (3) Product design, (4) Design validation, (5) Tested design. The subjects of this study were conducted by 3 experts (health promotion experts, nursing practitioners, and medical surgical nursing experts) and 10 clients with type II DM. In this study using a validation sheet from 3 experts by providing an assessment of the media used by researchers includes 3 aspects, including: aspects of 
the material, aspects of the content, and aspects of appearance. Analysis of the data used is qualitative descriptive analysis in the form of comments, suggestions, and criticisms from the validation sheet of 3 experts and quantitative descriptive analysis in the form of a Likert scale which has about a value of 1-5 from the validation sheet of experts. After obtaining an assessment score by the experts from the validation sheet, the percentage of eligibility is determined.

\section{RESULTS}

Table 1. Results from experts

\begin{tabular}{clcccc}
\hline \multirow{2}{*}{ No } & Expert & \multicolumn{2}{c}{ Validation Percentage } & & Cate gory \\
& Judgment & Validation I & Validation II & Validation III & \\
\hline 1. & Matery & $90 \%$ & $95 \%$ & $95 \%$ & Very decent \\
2. & Content & $95 \%$ & $95 \%$ & $95 \%$ & Very decent \\
3. & Display & $90 \%$ & $90 \%$ & $95 \%$ & Very decent \\
\hline
\end{tabular}

Based on the recapitulation table of the results of the validity test by 3 experts on the material aspects, the results of validation I $90 \%$ with the category of very feasible, the results of the validation II of $95 \%$ with the category of very feasible, the results of the validation of the $95 \%$ III with the category of very feasible. In the aspect of content, the result of validation I is $95 \%$ with a very decent category, the results of validation II are $95 \%$ with a very feasible category, the result of validation III is $95 \%$ with a very feasible category, and the display aspect shows that the results of the validation I are $95 \%$ with a very decent category. $95 \%$ in the very feasible category and the results of the validation III $95 \%$ in the very feasible category. The recapitulation of trial results is limited to 10 clients regarding DSME health through the WhatsApp application on type 2 DM clif 81 The recapitulation of trial results is presented in the following table.

Based on the recapitulation table, the results of the trial are limited to 10 respondents, the average result in the material aspect is $96.5 \%$ with a very decent category, the average yield for the understanding aspect is $95.5 \%$, with a very decent category and the average results in the display aspect is $96 \%$ with a very decent category.

\section{DISCUSSION}

In the development of health education media about DSME through the WhatsApp application on DM type II clients using research and development methods (R\&D) using the ADDIE model development method (Assume, Design, Development, Implementation, Evaluation). The steps in this research include: (1) potential problems and information gathering, (2) literature study, (3) Product design, (4) Design validation, (5) tested design. The initial step in this research is to know the potential problems and collection, based on literature studies that have been read by the results obtained that the health education media that have been given at hospitals in the city of Semarang are still using print media in the form of leaflets, flip sheets and booklets and there are no media health education in the form of pictures in the format of Power Point (PPT) that has been published by the Indonesian Ministry of Health in the field of P2PTM and is done by sending DSME education media through the WhatsApp 
application. The next step is to conduct a literature study on health education media which is carried out in a hospital.

The next step is to design a health media design on DSME through the WhatsApp application on DM type II clients. On DSME media, it was presented with the title "Healthy Living without Diabetes" for 4 sessions. To facilitate understanding of information presented in the form of images that have been published by the Indonesian Ministry of Health in the field of P2PTM in power point format. For session 1 discusses the basic concepts of DM, session 2 discusses the regulation of diet and physical activity, session 3 discusses foot care, session 4 discusses stress management, social support and utilization of health facilities.

After the draft health information about DSME has been completed, the next step is to carry out a validation test by an expert. In this study the validity test was conducted by 3 experts including: health promotion experts, nursing practitioners and surgical medical nursing experts. The validation test regarding health information about DSME for type 2 DM clients includes 3 aspects of assessment including: material, content and appearance aspects. The validation test process by the expert by sending a text draft with the power point format about DSME along with the assessment instrument via email then the expert provides an assessment by filling out a questionnaire that has been provided by the researcher. The validation test process by 3 experts carried out 1 time with different times. After validation testing is done by an expert, a limited trial is carried out. In this study, a limited trial was conducted on 10 clients. The limited trial was carried out by sending DSME PPT via WhatsApp to each individual in turn then filling out the assessment questionnaire covering 3 aspects including: aspects of appearance, material and understanding. In the final stage of this research and development, the DSME delivery design through the WhatsApp application in type 2 DM patients has been tested internally by 3 experts and externally ie the trial is limited to 10 clients, but in research and development Research and Development ( $\mathrm{R} \& \mathrm{D}$ ) by using the ADDIE model development method (Assume, Design, Development,Implementatoon, Evaluation) only up to product design testing, work system performance, production processes and production requirements or not, so it is necessary to develop the delivery of DSME through WhatsApp application on DM type 2 clients to get the feasibility of field trials, and can increase at the research and development level then to find out the level of effectiveness of DSME through WhatsApp application to increase knowledge in DM type 2 clients about selfmanagement to improve quality of life.

\section{CONCLUSION}

In this research a health education media about DSME was developed through the Whatsapp application on DM type II clients. The steps in developing health education media include: finding potential problems and gathering information, conducting literature studies, making product designs, validating designs and producing proven designs. The next researcher is expected to be able to continue the field trials with a wider sample (real type II DM clients) for effectiveness testing and client preparation for returning to DSME delivery via WhatsApp application on DM type II clients. 


\section{REFERENCE}

Ansari, Rashid M, John B Dixon, and Jan Coles. 2015. "Type 2 Diabetes: Challenges to Health Care System of Pakistan." International Journal of Diabetes Research 4(1): 7-12. This review article is aimed at describing the epidemic of type 2 diabetes in Pakistan and focusing particularly on the middle-aged population of Pakistan. Type 2 diabetes is a major public health problem in Pakistan as the middle- aged population in that.

Ekadinata, Nopryan, and Doni Widyandana. 2017. "Health Promotion Using Images and Text in WhatsApp Application on Posbindu Health Workers." Berita Kedokteran Masyarakat 33(11): 547.

Fitri, Dwi Elka, Siska Mayang Sari, and Tri Krianto. 2019. "The Comparison of the Comparison of Diabetes Self Management Education Using Lecturing Method with Booklet and Whatsapp Group Method against Self Care Behavior of Diabetes Mellitus Patients." Jurnal Kesehatan Komunitas 4(3): 126-31.

Hurtado, Maria Daniela, and Adrian Vella. 2019. "What Is Type 2 Diabetes?" Medicine (United Kingdom) 47(1): 10-15. 